\title{
The Effect of Social Network on Accptability of New Technology in Developing Countries: A Case Study of Piped Water Adoption in Rural India
}

\author{
Akiko Suzuki $^{1} \&$ Maiko Sakamoto ${ }^{1}$ \\ ${ }^{1}$ Dapartment of International Studies, Graduate School of Frontire Sciences, The University of Tokyo, Japan \\ Correspondence: 5-1-5, Kashiwanoha, Kashiwa-shi, Chiba 277-8561, Japan. Tel: 81-4-7136-4003. E-mail: \\ as.ffb05@gmail.com
}

Received: February 9, 2018

Accepted: February 23, 2018

Online Published: March 14, 2018

doi:10.5539/enrr.v8n2p1

URL: https://doi.org/10.5539/enrr.v8n2p1

\begin{abstract}
It has been pointed out that new technologies introduced in developing countries have not been accepted by local residents in some cases. It is assumed that new technologies need to be adapted to the local social structure if the aim is to generate sustainable technology acceptance. In this paper, the effect of social network on acceptability of new technologies is examined through a case study on piped water adoption in rural India. Social Network Analysis is used to investigate how closed social network groups and the centrality of some individuals in social network affect technology acceptance of residents. The effect of these attributes on technology acceptance is examined using logistic regression model. Our results show 3 main findings as follows: (1) there are no similarities of piped water use among residents belong to the same closed social network group, (2) central persons who affect other residents' technology use do not have high social status and play any role as a leader, thus, it is needed not to easily select persons who seem to be outstanding as key persons of technology adoption, (3) it is important to focus on not only individual attributes but also social network when new technologies are adapted.
\end{abstract}

Keywords: social network, technology acceptance, piped water adoption, India

\section{Introduction}

New technologies have been introduced in developing countries through international development assistance as an effective measure to meet their needs of building social infrastructure. However, it is pointed out that technologies adapted in developing countries have not been used properly and accepted consistently by local people (Ayabe, 2006). It has been discussed that if the aim is to support the sustainable use of new technologies, it is important to focus on not only quality of a technology itself but also the social and cultural backgrounds of the recipient society (Cernea, 1991; Edwars, 2006).

\subsection{Piped Water Adoption in Rural India}

In this paper, we focus on piped water adoption in rural India as an example of introduction of new technologies. As piped water is considerd easy-to-use technology, its non-acceptance by local people is assumed that the technology was not adapted to local social backgrounds.

Water supply projects in India have been at the forefront since the 2009 "National Rural Drinking Water Programme" (NRDWP), which promotes diffusion and maintenance of water supply facilities in rural areas (Ministry of Drinking Water and Sanitation Government of India, 2013). Under the NRDWP, the central government is in charge of planning and technical support while local governments are responsible for program implementation through "Piped Water Supply Schemes" (PWSS), which aims to introduce piped water in rural area. According to Sewak, Chowdhury \& Ghosh (2017), 55\% of rural population in India have access to piped water as of 2016.

One of the underlying motivations for this high profile initiative by the Indian government is the pressing need to take measures against arsenic contamination in groundwater. Since the discovery of high arsenic concentration in shallow tube-wells in the 1980's, which were widely used by rural households, safe water supply for rural areas became imperative concern (Chakraborti et al., 2009). As this issue was left unsolved for a long period in the country, diffusion of piped water as a means to ensure access to safe water is required. 


\subsection{Literature Review of Factors influencing Technology Acceptance}

There have been studies of the factors influencing technology acceptance. The relation between technology acceptance and social vulnerability is often discussed. For example, Negatu \& Parikh (1999) examined the agricultural technology adoption in Ethiopian farmers and found that the more the income is high, the more farmers tend to use new agricultural technologies. Moreover, Muneer \& Mohamed (2003) analyzed the determinants of installation of biomass cooking stoves in Sudanese households and demonstrated that the higher the level of the wifes' education, the more likely are new technologies to be accepted.

The risk perception of problems that caused the introduction of new technologies is considered as one of the factors of technology acceptance. Sakai, Yamamura, Hoque \& Hagihara (2003) examined the requirements of new technologies aiming to disseminate water supply and sanitation service in developing countries and argued that it is important to give priority to improve local people's risk perception of water and sanitation if the goal is to support adoption of new technologies. Rojas \& Megerle (2013) considered the determinants of water use behavior comparing satisfaction and risk perception of water quality. The study cocluded that people who understand the risk of water quality tend to use safe water more than people who consider that taste and color of water are important.

As described above, it has been demonstrated in various researches that individual attributes, namely, economic conditions, educational level, and risk perception affect technology acceptance. To be sure, those factors should be considered as one of the determinants for technology acceptance. However, Sato (1995) pointed out that international development assistance and projects including introduction of new technologies are conducted for the sake of local communities and thus, it is important to get a grasp of the local social structure. From this perspective, if these endeavors are to bring the sustainable introduction and adoption of these technologies, one should go beyond the analysis of individual attributes and incorporate elements of sturucture of local society.

The effect of "social network" on technology acceptance has been discussed to place importance on structure of local society over individual attributes. According to this branch of studies, others' use behavior and dissemination of information of new technologies in social network have an impact on technology acceptance (Udry \& Conely, 2004; Hoang, Castella \& Novosad, 2006; Isaac, Erickson, Quashie-Sam \& Timmer, 2007; Matuschke, 2008; Isaac, 2012). Moreover, comparing to developed countries, because of lack of access to information caused by underdeveloped internet services and low literacy rates, people in developing countries are more affected by social networks formed by informal relationships between people in real live. As such, it becomes imperative to consider the effect of social network on acceptability of new technologies in developing countries (Chuang \& Schechter, 2015).

As mentioned above, individual attributes and social network are regarded as the factors of technology acceptance. However, little speculation has taken place concerning these two factors by comparison. Therefore, we believe that combining these two analytical stands is essential for the development of comprehensive studies on sustainable technology adoption and acceptance.

\section{Objectives of the Study}

This paper attempts to analyze the factors of technology acceptance in developing countries by investigating both individual attributes and social network factors. We examine the effect of cohesive subgroups and central persons in social network on technology acceptance using Social Network Analysis.

In the light of the above, the purpose of this study is (1) to investigate how social network affect technology acceptance and (2) to consider the factors of acceptability of new technologies focusing on piped water adoption in rural India. Furthermore, in this paper we would like to generally analyze the effect of social network and individual attributes on technology acceptance.

\section{Method}

\subsection{Data Collection}

We conducted surveys in the village located on Nadia District, West Bengal, India. Piped water was introduced in the village ("Village C") in 2014 by the state government. We conducted two types of surveys, namely, questionnaire survey and hearing survey after the adoption of piped water. Survey respondents are residents who stayed home at that point of time in survey conducted on September 2014 and October 2015. Women who mainly play roles in collecting water in their households were selected as subjects in all surveys. Questionnaire surveys were carried out on September 2014 (T1) and October 2015 (T2). We collected 100 samples in T1 and 94 samples in T2. These questionnaire surveys included questions about the situation of water use, individual attributes, and social capital among residents. The hearing survey was conducted on September 2017, and 
covered questions about (1) quality and quantity of water sources, (2) satisfaction of water sources, and (3) a group of residents in Village $\mathrm{C}$.

\subsection{Data Analysis}

\subsubsection{Geographic Information System (GIS)}

Using GIS software, ArcGIS10.4, developed by Environmental Systems Research Institute, Inc., location of water source and households were visualized on the map of study area. In this paper, GIS is an effective tool to measure the distance between houses and water source and to grasp the relation between geographical conditions and piped water use.

\subsubsection{Social Network Analysis (SNA)}

SNA is designed to clarify the impact of social ties on individual behavior. A social network is composed of individuals, which are called "nodes", and of social relations between nodes, which are named "lines". There are two types of line: directed or undirected. The former is called an "arc", and the latter is an "edge" (Yasuda, 1994; Prell, 2012). Since the direction of nodes that may affect technology acceptance are key importance to this paper, we conduct SNA by use of arcs. Our social network mapping exercise was derived from the respondents' answers to the following question: "When you get in some troubles, with whom do you often talk?".

In this paper, two indices of SNA will be used as below.

(1) Cohesive subgroups:

Cohesive subgroups are composed of nodes which have close conecction with each other. It can be assumed that one individual's behavior has similarity with others who belong to same subgroup (De Nooy, Mrvar \& Batagelj, 2011). Thus, in analyzing cohesive subgroups is particularly useful for investigating similar behavior tendencies towards piped water use in a social network. In order to detect cohesive subgroups in a social network, one needs to identify strong components of nodes. Figure 1 shows a graphical representation of strong components. In this social network, nodes $\mathrm{A}, \mathrm{B}$, and $\mathrm{C}$ can reach other nodes by walking lines. Comparing to node $\mathrm{D}$ which is isolated in a network, nodes A, B, and C have strong components. Threfore, these three nodes can be considered as a cohesive subgroup.

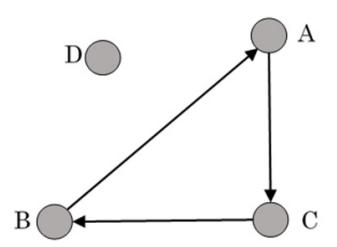

Figure 1. Strong components

\section{(2) Centrality:}

Centrality is often used as an index of SNA. One approach with which to measure centrality is called "degree centrality". "Degree" is number of lines one node has. When lines are directed, there are two types of degree: "outdegree" and "indegree". The former is the number of arcs it sends, whereas the latter is the number of arcs it receives (De Nooy et al., 2011). It seems that peoples' behavior is affected by the behavior of others who are perceived to be reliable. Thus, in our analysis we use indegree centrality for SNA, that is, how piped water use behavior of nodes who have high indegree centrality affect other nodes' piped water use behavior.

Figure 2 graphically describes indegree in a social network. Nodes A, B, and C were asked "When you get in some troubles, with whom do you often talk?". If nodes B and C answerd "node A", degrees from nodes B and C reach node A. Threfore, node A get 2 degrees from nodes B and C, namely, indegrees of node A is 2 . In a social network, the more indegrees nodes have, the higher their indegree centrality.

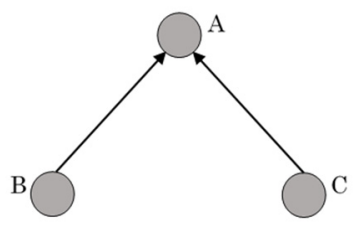

Figure 2. Indegree 


\subsubsection{Logistic Regression}

We use logistic regression to analyze the effect of social network and individual attributes on technology acceptance. Hosmer, Lemeshow \& Sturdivant (2013) and Ishiguro (2014) were used as references of theory and application of logistic regression.

Logistic regression is a statistical method to explain how much explanatory variables relate to an objective variable. This method is used when an objective variable is two-valued like 0 (absence/"no") to 1 (presence/"yes"). Odds of an objective variable taking 1 can be explained with formula of regression model below:

$$
\begin{gathered}
P=\frac{1}{1+\exp \left\{-b_{0}+b_{1} x_{1}+b_{2} x_{2}+\cdots+b_{p} x_{p}\right\}} \\
\ln _{\frac{P}{(1-P)}}=b_{0}+b_{1} x_{1}+b_{2} x_{2}+\cdots+b_{p} x_{p} \\
b_{0} \text { : constant, } b_{p} \text { : partial regression coefficient, } x_{p} \text { : covariate }
\end{gathered}
$$

\section{Results}

\subsection{Social and Economic Status of Subjects}

Table 1 shows social and economic status of survey respondents and of their households. With regards to monthly income, the "Rs.2,001-4,000" strata accounts for nearly $50 \%$ of the respondents. As average monthly income in rural India is around Rs.6,400 (Government of India, 2014), it can be conjectured that economic level in Village $\mathrm{C}$ is low. Also worth noticing is (1) the fact that about $60 \%$ of subjects have never got education or received only primary education and (2) that occupation of head of household is mainly self-owned farmer or

\begin{tabular}{|c|c|c|c|c|}
\hline & & & $\mathrm{n}$ & $\%$ \\
\hline \multirow[t]{6}{*}{ Hoseholed monthly income } & $\mathrm{n}=88$ & & & \\
\hline & & $\leqq$ Rs. 2,000 & 12 & 13.6 \\
\hline & & Rs.2,001-4,000 & 41 & 46.5 \\
\hline & & Rs.4,001-6,000 & 26 & 29.5 \\
\hline & & Rs.6,001-8,000 & 5 & 5.6 \\
\hline & & Rs. $8,000 \leqq$ & 4 & 4.5 \\
\hline \multirow[t]{5}{*}{ Number of family menbers living together } & $\mathrm{n}=88$ & & & \\
\hline & & $1 \sim 3$ & 19 & 21.5 \\
\hline & & $4 \sim 6$ & 49 & 55.6 \\
\hline & & $7 \sim 9$ & 18 & 20.4 \\
\hline & & $10 \leqq$ & 5 & 5.6 \\
\hline \multirow[t]{4}{*}{ Educational level } & $\mathrm{n}=88$ & & & \\
\hline & & No education & 34 & 38.6 \\
\hline & & Below secondary education & 18 & 20.4 \\
\hline & & Over secondary education & 36 & 40.9 \\
\hline \multirow[t]{3}{*}{ Literacy } & $\mathrm{n}=88$ & & & \\
\hline & & Yes & 56 & 62.9 \\
\hline & & No & 32 & 36.3 \\
\hline \multirow[t]{8}{*}{ Occupation of householder } & $\mathrm{n}=88$ & & & \\
\hline & & Self-owned farmer & 15 & 17.0 \\
\hline & & Employed farmer & 7 & 7.9 \\
\hline & & Self-owned businessman & 12 & 13.6 \\
\hline & & Employed businessman & 5 & 5.6 \\
\hline & & Daily laborer & 33 & 37.5 \\
\hline & & Rickshaw puller/Van driver & 1 & 1.1 \\
\hline & & Other & 15 & 17.0 \\
\hline
\end{tabular}
daily laborer.

Table 1. Social and economic status of subjects 


\subsection{Drinking Water Source}

4.2.1 Drinking water source in the study area

The location of drinking water sources in Village $\mathrm{C}$ is showed in Figure 3. Types of drinking water sources in the village are shallow tube-well, deep tube-well, and piped water. Detailed informations of these 3 drinking water sources are below.

public tap

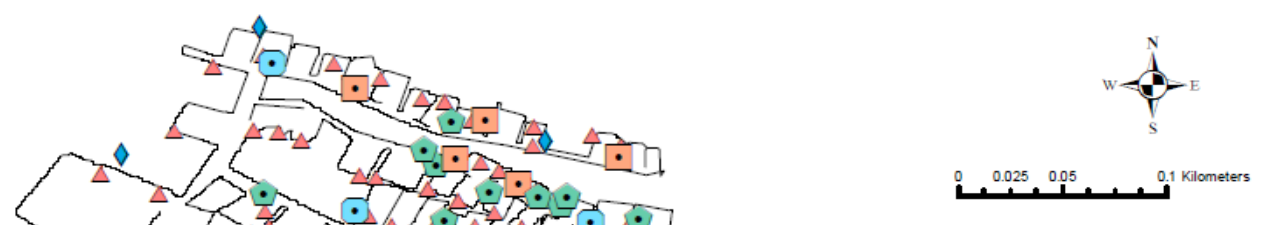

owned tap connected to public piped water (constructed by one household)

owned tap connected to public piped water (constructed by plural households)

shallow tube-well

$\diamond$ deep tube-well

Figure 3. Location of drinking water source in Village C

(1) Shallow tube-well

The source of shallow tube-wells are shallow aquifers (with depth ranging from 30-50m). As previously noted, since there is a risk of arsenic contamination for shallow tube-wells, this water source is regarded as unsafe. Arsenic tests conducted in Village $\mathrm{C}$ showed that most shallow tube-wells did contain arsenic. According to residents in Village $\mathrm{C}$, shallow tube-wells have large quantity of water and easy to access. However, in addition to arsenic contamination, water from shallow tube-well is tinny taste, thus the quality of this water source is quite inferior.

Figure 4 shows the results of the question "Do you know that there is a possibility that the shallow tube-well water may be arsenic contaminated?" which measures risk perception of arsenic contamination. In Village C, a study group of authors' research associate did a workshop to raise awareness of arsenic contamination. Nearly $60 \%$ of subjects answerd "Knows well" or "Knows" but then over $30 \%$ of subjects answerd "Knows little" or "Don't know".

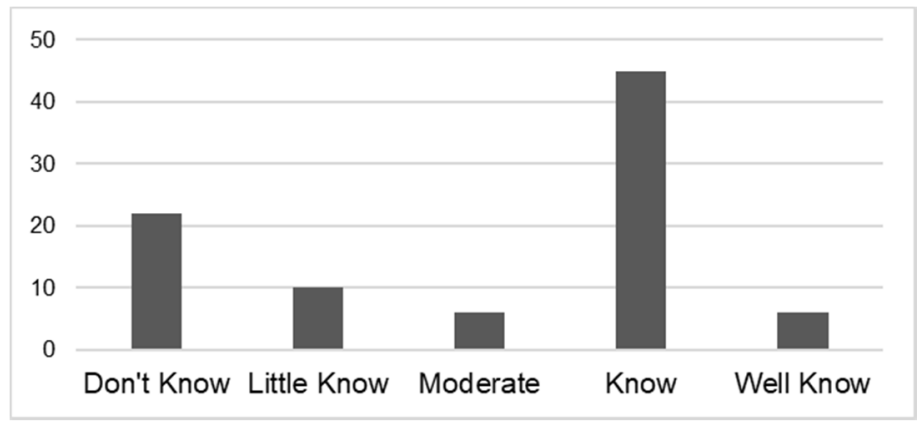

Figure 4. Risk perception of arsenic contamination 


\section{(2) Deep tube-well}

Deep tube-well is a type of a tube-well that is 150-200m deep. Deep tube-wells have been known as a safe water source, but recently it has been reported that this water source may also pose a potential risk of arsenic contamination (Burgess et al., 2010). Although there are some deep tube-wells introduced by the Indian government in Village $\mathrm{C}$, residents claimed that most of those are out of order. Therefore, residents must walk little distances when they want to use deep tube-well.

\section{(3) Piped water}

Public taps which were constructed by the state government have been used in Village C. In addition, despite its illegality, there are privately owned taps installed by residents which connect to public piped water. As for privately owned taps, there are two types as follows: (1) about 2-5 households bear construction costs to use piped water between themselves, (2) one household bears construction cost of these privately built piped water connections. According to residents, even residents who did not contribute to the construction cost can use privately built taps.

All the residents use piped water twice a day without charge, but according to them, sometimes no water is supplied via taps for a few days.

\subsubsection{Changing Patterns of Main Drinking Water Source}

We classified changing patterns of main drinking water source from T1 to T2. Table 2 shows the classification results. In total, we found 9 changing patterns of main drinking water source: patterns (1) and (2), namely, using piped water both in T1 and T2 or came to use piped water from T1 to T2, are "use piped water group". Pattern (3)-(9), namely, did not use piped water both in T1 and T2 or stop using piped water from T1 to T2 are grouped as "do not use piped water group". The ratio of "use piped water group" is $31.4 \%$, and "do not use piped water group" is $68.2 \%$.

Table 2. Changing patterns of main drinking water

\begin{tabular}{cccccc}
\hline piped water use & & Main drinking water source in T1 & Main drinking water source in T2 & $\mathrm{n}$ & $\%$ \\
\hline \multirow{2}{*}{ Use piped water } & $(1)$ & Piped water & Piped water & 28 & 31.8 \\
& $(2)$ & Deep tube-well & Piped water & 2 & 2.2 \\
& $(3)$ & Piped water & Piped water & 16 & 18.1 \\
& $(4)$ & Piped water & Shallow tube-well & 3 & 3.4 \\
& $(5)$ & Piped water & Bottled water & 6 & 6.8 \\
Do not use piped water & $(6)$ & Deep tube-well & Deep tube-well & 27 & 31.8 \\
& $(7)$ & Deep tube-well & Shallow tube-well & 1 & 1.1 \\
& $(8)$ & Shallow tube-well & Deep tube-well & 4 & 4.5 \\
& $(9)$ & Shallow tube-well & Shallow tube-well & 1 & 1.1 \\
\hline
\end{tabular}

\subsection{Analyses of the Factor of Technology Acceptance}

In this section, first we analyze how ties of nodes in the whole social network and cohesive subgroups affect piped water use. Then, the effect of connection with nodes which have high indegree centrality on piped water use will be examined. Finally, the impact of social network and individual attributes on piped water use will be revealed using logistic regression.

4.3.1 The Relation Between Ties of Nodes in the Whole Social Network/Cohesive Subgroups and Piped Water Use

\section{(1) The Relation Between Ties of Nodes in the Whole Social Network and Piped Water Use}

A social network was drawn using the answers of "When you get in some troubles, with whom do you often talk?". The effect of direct connection with nodes in the whole social network (i.e. before divided into cohesive subgroups) on piped water use was examined. The relation between having direct connection with a node which uses/does not use piped water and piped water use was analyzed through chi-square test. Table 3 shows the result. We found that nodes which have direct connections with a node which uses piped water tend to use piped water $(p<0.05)$. On the other hand, having direct connections with a node which does not use piped water and piped water use is statistically unrelated. 
Table 3. The relation between ties of nodes in the whole social network and piped water use

\begin{tabular}{|c|c|c|c|}
\hline & \multicolumn{2}{|c|}{ Piped water use } & \multirow[t]{2}{*}{$p$-value } \\
\hline & Uses piped water & Does not use piped water & \\
\hline $\begin{array}{l}\text { Direct connection with a node which uses } \\
\text { piped water }\end{array}$ & & & $0.033^{* *}$ \\
\hline Yes $\quad(n=50)$ & $22(44.0)$ & $28(56.0)$ & \\
\hline No $\quad(n=33)$ & $7(21.2)$ & $26(78.7)$ & \\
\hline $\begin{array}{l}\text { Direct connection with a node which does } \\
\text { not use piped water }\end{array}$ & & & n.s \\
\hline Yes $\quad(n=72)$ & $23(31.9)$ & $49(68.0)$ & \\
\hline$(\mathrm{n}=11)$ & $6(54.5)$ & $5(45.4)$ & \\
\hline
\end{tabular}

Note. n (\%), chi-square test, ${ }^{* *} p<0.05$, n.s $=$ not significant.

(2) The Relation Between Ties of Nodes in Cohesive Subgroups and Piped Water Use

Strongly connected subgroups were identified to analyze the impact of ties of nodes in cohesive subgroups on piped water use. Four cohesive subgroups ("Group1-4") were detected from the social network. In Figure 5, cohesive subgroups are boxed while nodes which are not boxed do not belong to any strongly connected subgroups.

The ratio of piped water use in each cohesive subgroup was compared using Fisher's exact test. Table 4 shows that there was no significant difference in piped water use between the four cohesive subgroups.

Since the number of nodes is much higher in Group 4, we further divided it into another groups. Consequently, two cohesive subgroups were detected from Group 4 ("Group 4-1", "Group4-2") shown in Figure 6. The ratio of piped water use in each of them was compared using chi-square test as shown in Table 5. It was revealed that there was no significant difference in piped water use between Group 4-1 and 4-2. Accordingly, it is assumed that there is no association between ties of nodes in cohesive subgroups and piped water use.

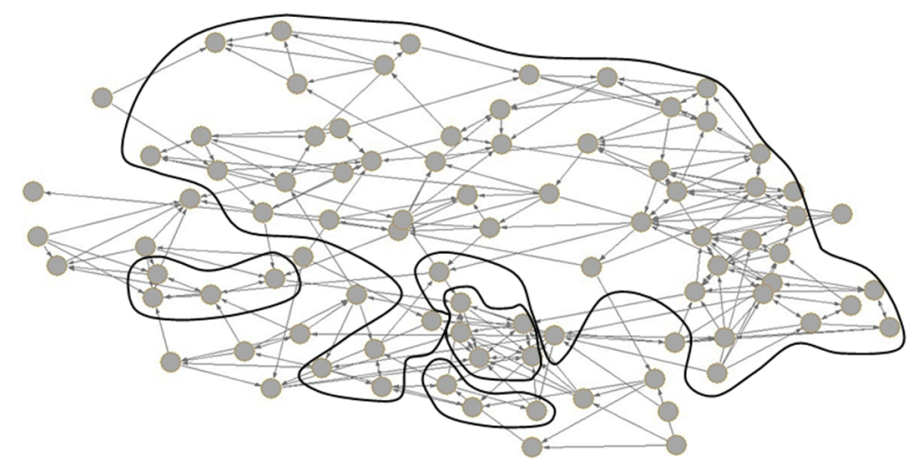

Figure 5. Four Cohesive subgroups

Table 4. The ratio of piped water use in four cohesive subgroups

\begin{tabular}{|c|c|c|c|c|}
\hline & & \multicolumn{2}{|c|}{ Piped water use } & \multirow[t]{2}{*}{$p$-value } \\
\hline & & Use piped water & Do not use piped water & \\
\hline Group 1 & $(n=5)$ & $0(0.0)$ & $5(100.0)$ & n.s \\
\hline Group 2 & $(n=3)$ & $0(0.0)$ & $3(100.0)$ & \\
\hline Group 3 & $(n=4)$ & $1(25.0)$ & $3(75.0)$ & \\
\hline Group 4 & $(\mathrm{n}=56)$ & $24(42.8)$ & $32(57.1)$ & \\
\hline
\end{tabular}

Note. n (\%), Fisher's exact test, n.s=not significant. 


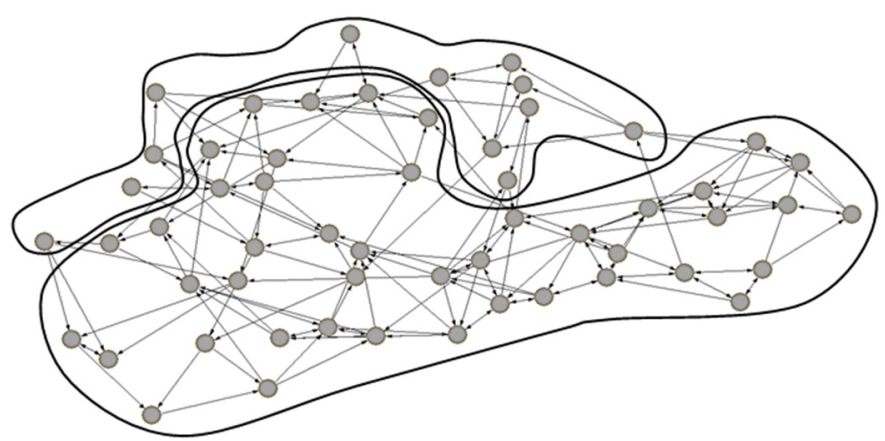

Figure 6. Two Cohesive subgroups

Table 5. The ratio of piped water use in Two cohesive subgroups

\begin{tabular}{lllll}
\hline & & \multicolumn{2}{c}{ Piped water use } & $p$-value \\
\cline { 3 - 4 } & & Use piped water & Do not use piped water & \\
\hline Group 4-1 & $(\mathrm{n}=12)$ & $7(58.3)$ & $5(41.6)$ & n.s \\
Group 4-2 & $(\mathrm{n}=44)$ & $17(38.6)$ & $27(61.3)$ & \\
\hline
\end{tabular}

Note. $\mathrm{n}(\%)$, chi-squared test, $\mathrm{n} . \mathrm{s}=$ not significant.

\subsubsection{The Effect of the Nodes with High Indegree Centrality on Piped Water Use}

\subsubsection{Identification of the Nodes with High Indegree Centrality}

Nodes with high indegree centrality were identified from the social network using the answers of "When you get in some troubles, with whom do you often talk?". As per our calculations of the number of indegree ranged from $0-8$ is shown in Figure 7. Nodes were classified in 5 groups according to the amount of indegree of nodes and Table 6 shows the results. The nodes which belong to Group 5 are "the nodes with high indegree centrality". Figure 8 shows the status of piped water use for nodes in Group 5. Among 10 nodes with high indegree centrality, four used piped water while six nodes did not.

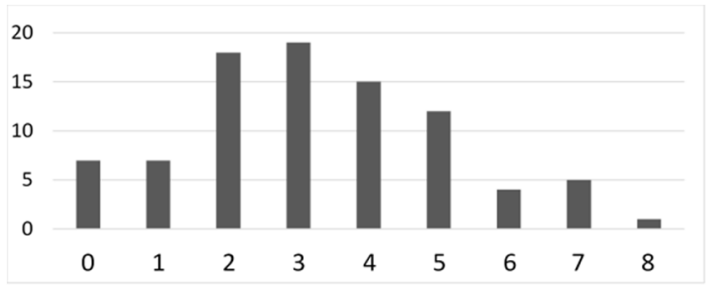

Figure 7. Indegree of nodes

Table 6. Classification of nodes in proportion to the amount of indegree

\begin{tabular}{cccccc}
\hline $\begin{array}{c}\text { Group } \\
\text { (indegree) }\end{array}$ & 1 & 2 & 3 & 4 & 5 \\
$(0)$ & $(1)$ & $(2 \cdot 3)$ & $(4 \cdot 5)$ & $(6 \cdot 7 \cdot 8)$ \\
\hline Number of nodes & 8 & 7 & 36 & 27 & 10 \\
\hline
\end{tabular}

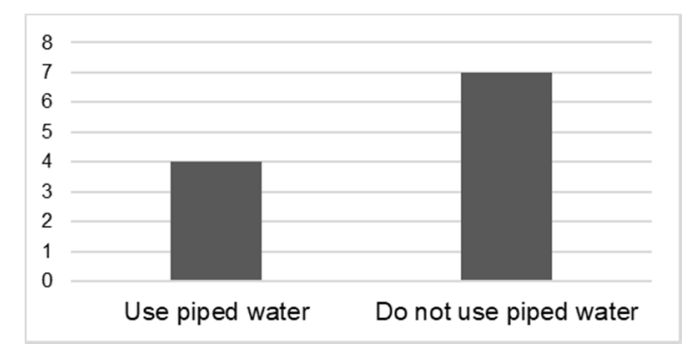

Figure 8. Piped water use of the nodes with high indegree centrality 


\subsubsection{Computation of the Distances to Nodes with High Indegree Centrality}

The "distance" between one node and the nodes with high indegeree centrality was calculated. "Distance" means number of steps to reach another node in a social network (De Nooy et al., 2011). Figure 9 shows the distances between nodes and one of the nodes with high indegree centrality which does not use piped water. The numbers written in each node is the number of arcs required to reach the nodes with high indegree centrality which does not use piped water. Nodes with no numbers written in them represent that it is impossible to reach nodes with high indegree centrality which does not use piped water.

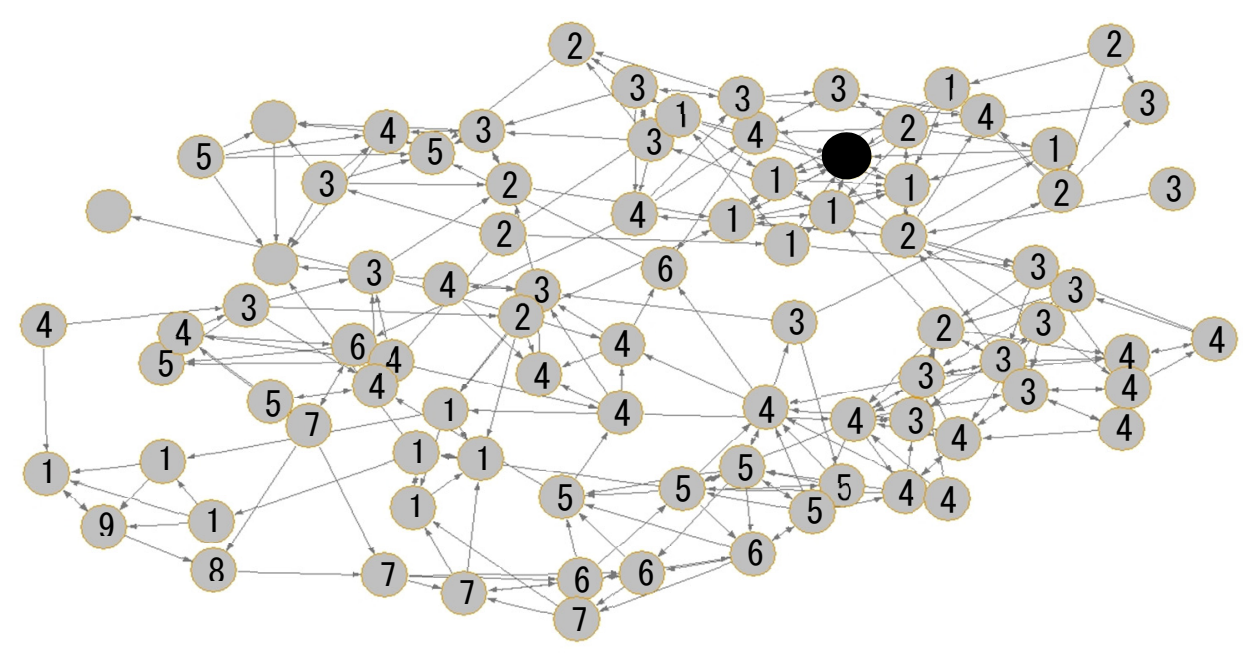

The node with high indegree centrality which does not use piped water

Figure 9. Distances between nodes and one of the nodes with high indegree centrality which does not use piped water

\subsubsection{The Relation Between Distances to the Nodes with High Indegree Centrality and Piped Water Use}

It can be said that if the distances to the nodes with high indegree centrality is small, then information is potentially more easily diffused. Accordingly, the relation between the distances to the nodes with high indegree centrality and piped water use was analyzed using $t$-test. Table 7 shows the result. We found that the association between the distances and piped water use was insignificant.

Table 7. The relation between distances to the nodes with high indegree centrality and piped water use

\begin{tabular}{llllll}
\hline & \multicolumn{4}{c}{ Piped water use } & \multirow{2}{*}{$t$-value } \\
\cline { 2 - 5 } & Use piped water & \multicolumn{2}{c}{ Do not use piped water } & \\
\hline & mean value & SD & mean value & SD \\
\hline $\begin{array}{l}\text { Distance to the nodes with high indegree centrality } \\
\text { which uses piped water (n=88) }\end{array}$ & 2.76 & 2.25 & 3.36 & 2.09 & 1.09 \\
\hline $\begin{array}{l}\text { Distance to the nodes with high indegree centrality } \\
\text { which does not use piped water } \quad 2.73\end{array}$ & & & & & \\
\hline
\end{tabular}

\subsubsection{The Relation Between Reachability to the Nodes with High Indegree Centrality and Piped Water Use}

Figure 10 shows total number of nodes for which it is impossible to reach the nodes with high indegree centrality which use/do not use piped water. We found that the former occurred more frequently than the latter. Therefore, we analyzed the relation between reachability to the nodes with high indegree centrality and piped water use through chi-square test and Fisher's exact test. Table 8 shows the result. We found that there was a significant effect of reachability to the nodes with high indegree centrality that use piped water on piped water use $(p<0.10)$. On the other hand, reachability to the nodes with high indegree centrality which do not use piped water was not significantly associated with piped water use. 


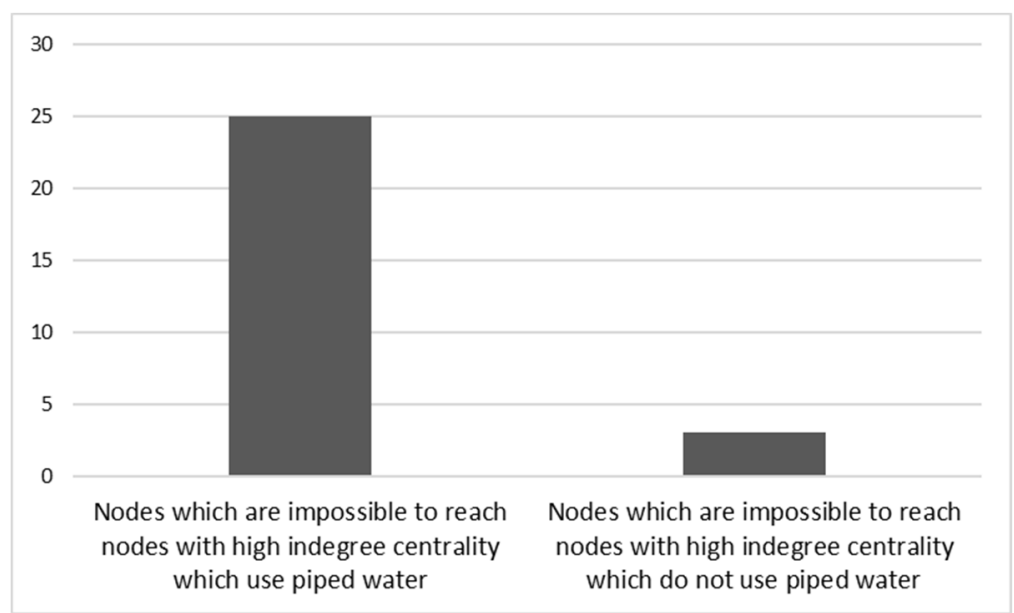

Figure 10. Total number of nodes which are imposible to reach the nodes with high indegree centrality which used/did not use piped water

Table 8 . The relation between reachability to the nodes with high indegree centrality and piped water use

\begin{tabular}{|c|c|c|c|c|}
\hline \multirow{3}{*}{$\begin{array}{l}\text { Reachability to the nodes with high indegree } \\
\text { centrality which use piped water } \dagger\end{array}$} & & \multicolumn{2}{|l|}{ Piped water use } & \multirow[t]{2}{*}{$p$-value } \\
\hline & & $\begin{array}{c}\text { Use piped water } \\
(\mathrm{n}=30)\end{array}$ & $\begin{array}{l}\text { Do not use piped water } \\
(\mathrm{n}=58)\end{array}$ & \\
\hline & $\begin{array}{l}\text { Possible } \\
\text { impossible }\end{array}$ & $\begin{array}{l}25(83.3) \\
5(16.6)\end{array}$ & $\begin{array}{l}38(65.5) \\
20(34.4)\end{array}$ & $0.079 *$ \\
\hline $\begin{array}{l}\text { Reachability to the nodes with high indegree } \\
\text { centrality which do not use piped water } \$\end{array}$ & $\begin{array}{l}\text { possible } \\
\text { impossible }\end{array}$ & $\begin{array}{l}30(100.0) \\
0(0.0)\end{array}$ & $\begin{array}{l}56(96.5) \\
2(3.4)\end{array}$ & n.s \\
\hline
\end{tabular}

Note. n $(\%), \dagger$ chi-square test, + Fisher's exact test, ${ }^{*} p<0.1$, n.s $=$ not significant.

\subsubsection{The effect of social network and individual attributes on piped water use}

We used logistic regression modeling to estimate the effect of social network and individual attributes on piped water use.

\subsubsection{Variables Used in Logistic Regression}

Two models were estimated for logistic regression analysis. In Model 1, "direct connection with a node which uses/does not use piped water" was used as an explanatory variable related to social network. On the other hand, in Model 2, "direct connection with a node with high indegree centrality which uses/does not use piped water" was used as explanatory variable related to social network. Objective variable and all explanatory variables used in logistic regression are shown in Table 9. The variables "household monthly income level" and "educational level", were used to examine the relation between individual attributes and technology acceptance that were pointed out in previous researches. "Ease of access to medicine" was used as an explanatory variable because it is assumed that risk prevention of disease caused by drinking unsafe water would decrease if people could get medicine easily. 
Table 9. Variables used in the logstic regression analysis

\begin{tabular}{|c|c|c|}
\hline & Variable name & Values \\
\hline \multirow[t]{3}{*}{ Objective variable } & Piped water use & Use piped water="1", Do not use piped water="0" \\
\hline & Household monthly income level & $\leqq$ Rs. $2000=" 1 "$, Rs. $2001 \sim 4000=" 2 "$, Rs. $4001 \sim 6000=" 3 "$, Rs. $6001 \sim 8000=" 4 "$, Rs. $8000 \leqq$ \\
\hline & & $=" 5 "$ \\
\hline \multirow{5}{*}{$\begin{array}{l}\text { Explanatory variable (related to } \\
\text { individual attributes) }\end{array}$} & Educational level & No education="0", Below secondary education="1", Over secondary education="2" \\
\hline & Ease of access to medicine & Very difficult="1", Difficult="2", Not either="3", Easy="4", Very Easy="5" \\
\hline & Distance between house and piped water & \\
\hline & Risk awareness of arsenic contamination & Don’t know="1", Little know="2", Moderate="3", Know="4", Well know="5" \\
\hline & Direct connection with a node which & Yes="1", $\mathrm{No}=" 0 "$ \\
\hline \multirow{4}{*}{$\begin{array}{l}\text { Explanatory variable (related to } \\
\text { social network) }\end{array}$} & uses/does not use piped water & \\
\hline & Direct connection with a node with high & Yes="1", No="0" \\
\hline & indegree centrality which uses/does not use & \\
\hline & piped water & \\
\hline
\end{tabular}

\subsubsection{Estimated Results}

\section{(1) Estimated result of Model 1}

Table 10 shows the estimated result of Model 1. We found that "ease of access to medicine" and "direct connection with a node which uses piped water" is significantly associated with piped water use. The result showed a negative coefficient for "ease of access to medicine", so we can assume that the easier the access to medicine is easy, the more likely it is that residents do not use piped water $(p<0.10)$, that is, attention to safe water use decreases if residents can get medicine easily. Our estimation also showed that the coefficient for "direct connection with a node which uses piped water" is positive, that is, residents who have direct connection with a node which uses piped water tend to use piped water themselves $(p<0.10)$.

Table 10. Estimation result of Model 1

\begin{tabular}{lcc}
\hline & coefficient & $p$-value \\
\hline Household monthly income level & 0.131 & n.s \\
Educational level & 0.175 & n.s \\
Ease of access to medicine & -0.518 & $0.060^{*}$ \\
Distance between house and piped water & -0.012 & $\mathrm{n} . \mathrm{s}$ \\
Risk awareness of arsenic contamination & -0.205 & $\mathrm{n} . \mathrm{s}$ \\
Direct connection with a node which uses piped water & 1.050 & $0.090^{*}$ \\
Direct connection with a node which does not use piped water & -0.189 & $\mathrm{n} . \mathrm{s}$ \\
\hline
\end{tabular}

Note. Pseudo R-squared: 0.103 , multicollinearity: $1.25,{ }^{*} p<0.10, \mathrm{n} . \mathrm{s}=$ not significant.

\section{(2) Estimated result of Model 2}

Table 11 shows the estimated result of Model 2. Our estimation revealed that explanatory variables measuring the effect of social network, namely, "direct connection with a node with high indegree centrality which uses piped water" and "direct connection with a node with high indegree centrality which does not use piped water" are significantly related with piped water use. On the other hand, all explanatory variables related to the effect of individual attributes are not significantly associated with piped water use. First, there is positive correlation between "direct connection with a node with high indegree centrality which uses piped water" and piped water use. As such, according to the model we can assume that, residents who have direct connection with high indegree centrality which uses piped water tend to use piped water themselves $(p<0.05)$. Second, we found a negative correlation between "direct connection with a node with high indegree centrality which does not use piped water" and piped water use. As such, one can argue that residents who do not have direct connection with a node with high indegree centrality tend to use piped water $(p<0.10)$. 
Table 11. Estimated result of Model 2

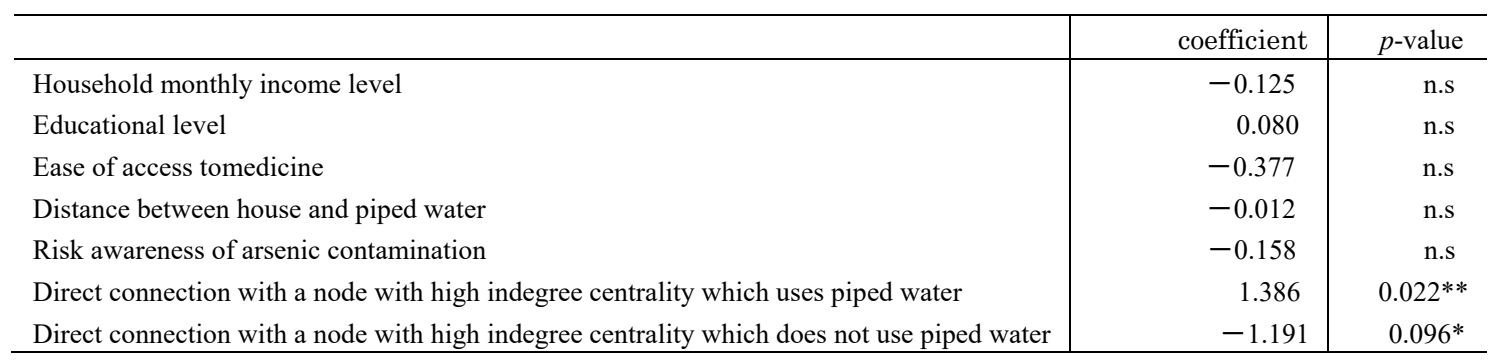

Note. Pseudo R-squared: 0.140 , multicollinearity: $1.11,{ }^{*} p<0.10,{ }^{*} p<0.05$, n.s $=$ not significant

\section{Discussion}

This section discusses the results of the effect of social network on piped water use as per the results of the abovementioned statistical analysis.

\subsection{The Relation Between Ties of Nodes in the Whole Social Network/Cohesive Subgroups and Piped Water Use}

First, when we analyzed the relation between ties of nodes in the whole social network, we discovered that nodes which have direct connection with piped water user nodes tend to use piped water themselves. In contrast, when nodes were devided into cohesive subgroups, there was no association between ties of nodes in cohesive subgroups and piped water use. Consiquently, we can assume that there is no similarity of piped water use among nodes which belong to same cohesive subgroups. In fact, ties of individual nodes in the whole social network affect piped water use.

\subsection{The Effect of Distance and Reachability to the Nodes with High Indegree Centrality on Piped Water Use}

Our estimation found no significant association between the distance to the nodes with high indegree centrality and piped water use. As for reachablity to the nodes with high indegree centrality, our model revealed that reachability to the nodes with high indegree centrality is significantly related with piped water use. On the other hand, we found no significant association between the distance to the nodes with high indegree centrality and piped water use.

As in Figure 10 (repeated below), the number of nodes for which it is impossible to reach high indegree centrality piped water user nodes is higher than the total number of nodes which are impossible to reach the nodes with high indegree centrality which do not use piped water. Accordingly, it is assumed that the nodes with high centrality that use piped water have less direct and indirect connections with other nodes. It is thus, more difficult to spread the behavior of piped water use.

\subsection{The Effect of Social Network and Individual Attributes on Piped Water Use}

We developed two models to examine the effect of social network and individual attributes on piped water use through logistic regression. In Model 1, "direct connection with a node which uses/does not use piped water" was used as explanatory variables measuring the effect of social network. Estimaton result showed that explanatory variables measuring the effect of both social network and individual attributes were significantly correlated with piped water use. In Model 2, the explanatory variables measuring the effect of social network was "direct connection with a node with high indegree centrality which uses/does not use piped water". The estimated results from this model revelaed that only the explanatory variables measuring the effect of social network were significantly associated with piped water use. In other words, all explanatory variables measuring the effect of individual attributes were not significantly associated with piped water use. Comparing Pseudo $\mathrm{R}$-squared and $p$-value of the two models, Model 2 indicated higher values than Model 1. Therefore, the result of Model 2 is more effective. As a result, we can assume about the effect of explanatory variables measuring social network that having a connection with the nodes with high indegree centrality more largely affects piped water use. In short, the nodes with high indegree centrality induce other nodes' behavior to use piped water.

\subsection{Attributes of the Nodes with High Indegree Centrality}

As mentioned above, we found that the nodes with high indegree centrality have an effect on piped water use of other nodes. Accordingly, attributes of the nodes with high indegree centrality will be analyzed in this section to investigate the reason why the nodes are central persons in the social network. Attributes of the nodes with high indegree centrality will be analyzed from the perspect of individual attributes and community association. 


\section{(1) Individual Attributes}

Table 12 shows "occupation of householder", "household monthly income level", and "educational level" of the groups of indegree centrality (shown before in Table 6). We found no significant difference in the three abovementioned factors between groups of indegree centrality. Therefore, it seems that the nodes with high indegree centrality (Group 5) do not have especially high social status.

Table 12. Individual attributes of the groups of indegree centrality

\begin{tabular}{|c|c|c|c|c|c|c|c|}
\hline & & \multicolumn{5}{|c|}{ Group of indegree centrality } & \multirow[t]{2}{*}{$p$-value } \\
\hline & & $\begin{array}{c}1 \\
(n=8)\end{array}$ & $\begin{array}{c}2 \\
(n=7)\end{array}$ & $\begin{array}{c}3 \\
(n=36) \\
\end{array}$ & $\begin{array}{c}4 \\
(\mathrm{n}=27)\end{array}$ & $\begin{array}{c}5 \\
(n=10)\end{array}$ & \\
\hline \multirow{7}{*}{ Occupation of householder $\dagger$} & Self-owned farmer & $2(25.0)$ & $2(28.5)$ & $6(16.6)$ & $3(11.1)$ & $2(20.0)$ & \\
\hline & Employed farmer & $0(0.0)$ & $1(14.2)$ & $2(5.5)$ & $3(11.1)$ & $1(10.0)$ & \\
\hline & Self-owned businessman & $0(0.0)$ & $2(28.5)$ & $4(11.1)$ & $4(14.8)$ & $2(20.0)$ & \\
\hline & Employed businessman & $1(12.5)$ & $0(0.0)$ & $1(2.7)$ & $2(7.4)$ & $1(10.0)$ & \\
\hline & Dily laborer & $4(50.0)$ & $2(28.5)$ & $18(50.0)$ & $7(25.9)$ & $2(20.0)$ & \\
\hline & Rikishaw puller/van driver & $0(0.0)$ & $0(0.0)$ & $1(2.7)$ & $0(0.0)$ & $0(0.0)$ & \\
\hline & Any other & $1(12.5)$ & $0(0.0)$ & $4(11.1)$ & $8(29.6)$ & $2(20.0)$ & \\
\hline \multirow{5}{*}{ Household monthly income level } & 1 & $2(25.0)$ & $0(0.0)$ & $5(13.8)$ & $3(11.1)$ & $2(20.0)$ & \\
\hline & 2 & $4(50.0)$ & $4(57.1)$ & $18(50.0)$ & $11(40.7)$ & $4(40.0)$ & \\
\hline & 3 & $2(25.0)$ & $2(28.5)$ & $10(27.7)$ & $8(29.6)$ & $4(40.0)$ & \\
\hline & 4 & $0(0.0)$ & $1(14.2)$ & $2(5.5)$ & $2(7.4)$ & $0(0.0)$ & \\
\hline & 5 & $0(0.0)$ & $0(0.0)$ & $1(2.7)$ & $3(11.1)$ & $0(0.0)$ & \\
\hline \multirow{3}{*}{ Educational level } & No education & $3(37.5)$ & $3(42.8)$ & $14(38.8)$ & $11(40.7)$ & $3(30.0)$ & \\
\hline & Below secondary education & $3(37.5)$ & $2(28.5)$ & $9(25.0)$ & $2(7.4)$ & $2(20.0)$ & \\
\hline & Over secondary education & $2(25.0)$ & $2(28.5)$ & $13(36.1)$ & $14(51.8)$ & $5(50.0)$ & \\
\hline
\end{tabular}

Note. $\mathrm{n}(\%), \dagger$ Fisher's exact test, otherwise Kruskal-Wallis test, n.s $=$ not significant.

Household monthly income level: $\leqq$ Rs. $2000=1$, Rs.2001 4000=2,Rs. 4001 6000=3, Rs.6001 8000=4, Rs. $8000 \leqq=5$.

\section{(2) Community Association}

There are community associations in Village C called "Self Help Group" (SHG), which is a major microfinance group in India composed of women. According to Village C residents, there are 12 13 members in one SHG and three of them share leadership roles. However, based on the results of hearing survey, none of persons with high indegree centrality played the role as a SHG leader. According to residents, persons who have high indegree centrality are trusted because they give advice to everyone and treat everyone fairly. In other words, persons who have high indegree centrality are regarded as reliable because of their behavior in daily life.

\section{Conclusion}

This paper explored the potential effect of social network on acceptability of new technologies in developing countries with the case of piped water adoption in rural India. At first, our results showed that there were no similarities between nodes that belong to same cohesive subgroup. It was also revealed that ties of nodes in the whole social network affect piped water use. Consequently, in some cases it may not be appropriate to introduce new technologies based on the assumption that technology use by residents in a closed community would be similar. Therefore, we argued that relational aspect of resident units needs to be considered.

In this study we analyzed the factor of technology acceptance using two logistic regression models. As an estimated result of Model 2, which used "direct connection with a node with high indegree centrality which uses/does not use piped water" as the explanatory variable for measuring social network impact, we found no correlation between individual attributes and piped water use. According to our results, piped water use is associated only with social network: we found that piped water use of the residents with high indegree centrality affect other residents' piped water use. Furthermore, we should emphasize that it is important to focus on not only individual attributes but also social network when new technologies are adapted. 
Our estimations also suggest that piped water use of residents who have high indegree centrality affects other residents' piped water use. One can thus argue that it seems effective to appeal to central figures in a social network when encouraging the use of new technologies. Outsiders often assume that residents who play role as a leader are suitable for diffusing new technology use to other residents, but our study shows that in some cases residents who do not have high social standing can also be regarded as central persons in their daily life. Accordingly, a more careful study of social network interactions may be needed before choosing residents who have social power or leadership to act as catalysts for the introduction and diffusion of new technologies.

In our analysys, we classified changing patterns of main drinking water. Since there are few subjects who use or came to use shallow tube-well which are arsenic contaminated, here we show attributes of those subjects. At first, subjects who have changed the main drinking water source from piped water to shallow tube-well have no similarity in individual attributes and risk awareness of arsenic contamination. However, they have a characterisic in common, namely, they have no direct connection with residents who use piped water. Next, there is a subject who has used shallow tube-well constantly. We found that risk awareness level of arsenic contamination for the subject is the lowest. As such, we also believe that initiatives to raise awareness about arsenic contamination risks are needed.

This study, however, suffers from some limitations. First, we did not consider proper use of drinking water source of residents: since residents rarely use only one drinking water source, there is a need to examine how residents accept piped water in the situation of proper use of drinking water source. Second, this study analyzed the data collected in one village and limited number of samples. Therefore, similar studies in different social backgrounds and about the introduction of different types of technology should be conducted before being able to make generalizations about our findings.

\section{Acknowledgments}

The authors acknowledge the support of Dr. Sudhin Mukhopadhyay, Dr. Kasturi Bakshi, and Ms. Saswati Roy (KINSPARC) for the fieldwork. We also appreciate the comments of Mr. Stefano Berriel da Silva for the development of the manuscript. This study was supported by Grant-in-Aid for JSPS Research Fellow 26703002.

\section{References}

Ayabe, M. (2006). On the Diversity of Technological Acceptance in the International Technology Transfer. Nihon Fukushi University, the journal of economic studies, 32, 201-213.

Burgess, W. G., Hoque, M. A., Michael, H. A., Voss, C. I., Breit, G. N., \& Ahmed, K. M. (2010). Vulnerability of deep groundwater in the Bengal Aquifer System to contamination by arsenic. Nature Geoscience, 3(2), 83-87.

Cernea, M. (1991). Putting People First (2nd ed.). Oxford: Oxford University Press.

Chakraborti, D., Das, B., Rahman, M. M., Chowdhury, U. K., Biswas B., Goswami A. B., ... Das, D. (2009). Status of groundwater arsenic contamination in the state of West Bengal, India: A 20year study report. Molecular Nutrition \& Food Research, 53(5), 542-551.

Chuang, Y., \& Schechter, L. (2015). Social networks in developing countries. Annu. Rev. Resour. Econ., 7(1), 451-472.

De Nooy, W., Mrvar, A., \& Batagelj, V. (2011). Exploratory social network analysis with Pajek. 27. Cambridge University Press.

Edwards, M. (1999). Future positive. International Cooperation in the 21st Century.

Government of India. (2014). Key Indicators of Situation of Agricultural Households in India. NSS $70^{\text {th }}$ Round.

Hoang, L. A., Castella, J. C., \& Novosad, P. (2006). Social networks and information access: Implications for agricultural extension in a rice farming community in northern Vietnam. Agriculture and Human Values, 23(4), 513-527.

Hosmer. Jr., Lemeshow, S., \& Sturdivant, R. X. (2013). Applied logistic regression. John Wiley \& Sons.

Isaac, M. E. (2012). Agricultural information exchange and organizational ties: The effect of network topology on managing agrodiversity. Agricultural systems, 109, 9-15.

Isaac, M. E., Erickson, B. H., Quashie-Sam, S. J., \& Timmer, V. R. (2007). Transfer of knowledge on agroforestry management practices: the structure of farmer advice networks. Ecology and society, 12(2).

Ishiguro, I. (2014). The analysis of social survey data using STATA: From guide to application. Kitaohjisyobo. 
Matuschke, I. (2008). Evaluating the impact of social networks in rural innovation systems: An overview. 816, Intl Food Policy Res Inst.

Ministry of Drinking Water and Sanitation, Government of India. (2013). National Rural Drinking Water Programme. Retrieved from http://mdws.gov.in/sites/default/iles/NRDWP_Guidelines_2013.pdf

Muneer, S. E. T., \& Mohamed, E. W. M. (2003). Adoption of biomass improved cookstoves in a patriarchal society: an example from Sudan. Science of the total environment, 307(1), 259-266.

Negatu, W., \& Parikh, A. (1999). The impact of perception and other factors on the adoption of agricultural technology in the Moret and Jiru Woreda (district) of Ethiopia. Agricultural economics, 21(2), 205-216.

Prell, C. (2012). Social network analysis: History, theory and methodology. Sage.

Rojas, L. F. R., \& Megerle, A. (2013). Perception of water quality and health risks in the rural area of Medellín. American Journal of Rural Development, 1(5), 106-115.

Sakai, A., Yamamura, S., Hoque, B. A., \& Hagihara, Y. (2003). About appropriate technology concept about water and hygiene. Proceedings of 31st Annual Meeting of Environmental Systems Research, 491-496.

Sato, K. (1995). Intrinsic factors of aids and society-Economic cooperation series, (177). Institute of Developing Ecnomies.

Sewak, P., Chowdhury, S., \& Ghosh, P. (2017). Har Ghar Jal by 2030: Current Status and Next Steps. Safe Water Network.

Udry, C. R., \& Conley, T. G. (2004). Social Networks in Ghana. Discussion Paper 888. New Haven: Yale University Economic Growth Center.

Yasuda, Y. (1994). Social network analysis: Theoretical background and measurements. The Japanese journal of Behaviormetrics, 21(2), 32-39.

\section{Copyrights}

Copyright for this article is retained by the author(s), with first publication rights granted to the journal.

This is an open-access article distributed under the terms and conditions of the Creative Commons Attribution license (http://creativecommons.org/licenses/by/4.0/). 